Published in final edited form as:

Gastroenterology. 2019 July ; 157(1): 137-148. doi:10.1053/j.gastro.2019.03.023.

\title{
Cost-Effectiveness and National Effects of Initiating Colorectal Cancer Screening for Average-Risk Persons at Age 45 Years Instead of 50 Years
}

\author{
Uri Ladabaum ${ }^{1}$, Ajitha Mannalithara ${ }^{1}$, Reinier G. S. Meester ${ }^{1}$, Samir Gupta ${ }^{2}$, Robert E. \\ Schoen $^{3}$ \\ ${ }^{1}$ Division of Gastroenterology and Hepatology, Department of Medicine, Stanford University \\ School of Medicine, Stanford, California; \\ ${ }^{2}$ Veterans Affairs San Diego Healthcare System, Division of Gastroenterology, Department of \\ Internal Medicine, Moores Cancer Center, University of California-San Diego, San Diego, \\ California; \\ ${ }^{3}$ Division of Gastroenterology, Hepatology and Nutrition, and Department of Epidemiology, \\ University of Pittsburgh, Pittsburgh, Pennsylvania
}

\section{Abstract}

BACKGROUND \& AIMS: The American Cancer Society has recommended initiating colorectal cancer (CRC) screening at age 45 years instead of 50 years. We estimated the cost effectiveness and national effects of adopting this recommendation.

METHODS: We compared screening strategies and alternative resource allocations in a validated Markov model. We based national projections on screening participation rates by age and census data.

RESULTS: Screening colonoscopy initiation at age 45 years instead of 50 years in 1000 persons averted 4 CRCs and 2 CRC deaths, gained 14 quality-adjusted life-years (QALYs), cost $\$ 33,900$ / QALY gained, and required 758 additional colonoscopies. These 758 colonoscopies could instead be used to screen 231 currently unscreened 55-year-old persons or 342 currently unscreened 65 year-old persons, through age 75 years. These alternatives averted 13-14 CRC cases and 6-7 CRC deaths and gained 27-28 discounted QALYs while saving \$163,700-\$445,800. Improving colonoscopy completion rates after abnormal results from a fecal immunochemical test yielded greater benefits and savings. Initiation of fecal immunochemical testing at age 45 years instead of 50 years cost $\$ 7700 /$ QALY gained. Shifting current age-specific screening rates to 5 years earlier

Address requests for reprints to: Uri Ladabaum, MD, MS, Division of Gastroenterology and Hepatology, Stanford University School of Medicine, 430 Broadway Street, Pavilion C, 3rd Floor C-326, Redwood City, California 94063-6341. uri.ladabaum@ @tanford.edu; fax: 650-724-0533.

Supplementary Material

Note: To access the supplementary material accompanying this article, visit the online version of Gastroenterology at www.gastrojournal.org, and at https://doi.org/10.1053/j.gastro.2019.03.023.

Conflicts of interest

This author discloses the following: Uri Ladabaum serves on the advisory board for UniversalDx and Lean Medical and as a consultant to Covidien, Motus GI, Quorum, and Clinical Genomics. The remaining authors disclose no conflicts. 
could avert 29,400 CRC cases and 11,100 CRC deaths over the next 5 years but would require10.7 million additional colonoscopies and cost an incremental \$10.4 billion. Improving screening rates to $80 \%$ in persons who are 50-75 years old would avert nearly 3-fold more CRC deaths at one third the incremental cost.

CONCLUSIONS: In a Markov model analysis, we found that starting CRC screening at age 45 years is likely to be cost effective. However, greater benefit, at lower cost, could be achieved by increasing participation rates for unscreened older and higher-risk persons.

\section{Graphical Abstract}

\begin{tabular}{|c|c|c|c|}
\hline & $\begin{array}{l}\text { Colonoscopy at ages } \\
45-75 \text { years vs. } \\
50-75 \text { years }\end{array}$ & $\begin{array}{l}\text { Colonoscopy at ages } \\
55-75 \text { years vs. } \\
\text { remain unscreened }\end{array}$ & $\begin{array}{l}\text { Colonoscopy at ages } \\
65-75 \text { years vs. } \\
\text { remain unscreened }\end{array}$ \\
\hline $\begin{array}{l}\text { People screened } \\
(x 100)\end{array}$ & เั่ & $\dot{2} \dot{i}$ & $\dot{i} i$ \\
\hline $\begin{array}{l}\text { Incremental colonoscopies } \\
(\times 100)\end{array}$ & ๑๑๑๑や๑๑ & 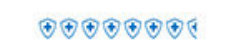 & 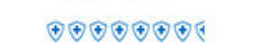 \\
\hline Colorectal cancers prevented & $\dot{0} \dot{0}$ & 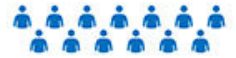 & 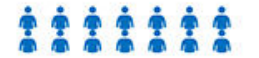 \\
\hline $\begin{array}{l}\text { Colorectal cancer deaths } \\
\text { prevented }\end{array}$ & $\dot{m}$ & $\dot{m} \dot{i} \dot{i}$ & $\dot{0} \dot{0} \dot{0}$ \\
\hline $\begin{array}{l}\text { Life-years gained } \\
\text { (x 10, discounted) }\end{array}$ & [i] $[5$ & [1] [1] $[\ddot{i}$ & [i] [i] \\
\hline $\begin{array}{l}\text { Costs \$ vs. Savings } \$ \\
\text { (x } \$ 100 \% \text {, discounted) }\end{array}$ & \$\$\$\$ & $\$ \$$ & $\begin{array}{l}\text { \$\$\$\$ } \\
\text { Gastroenterology }\end{array}$ \\
\hline
\end{tabular}

\section{Keywords}

Colon Cancer; Screening; Prevention; Cost-Effectiveness

Colon and rectal cancer incidence rates in 40-49-year-olds in the United States have increased over the last 2 decades by $1.3 \%$ and $2.3 \%$ per year, respectively. ${ }^{1}$ In contrast, incidence rates in persons over age 55 years have decreased by 2 - to 3 -fold more. ${ }^{1}$ Screening decreases colorectal cancer (CRC) incidence and mortality, ${ }^{2-6}$ and it is likely that increasing participation in CRC screening has contributed substantially to the decreasing CRC incidence in older Americans. ${ }^{7}$

The rising incidence of CRC in younger persons ${ }^{1}$ led the American Cancer Society (ACS) to recommend initiating average-risk CRC screening at age 45 years. ${ }^{8}$ This recommendation represents a major change to the previous consensus to initiate screening at age 50 years, as is recommended by the US Preventive Services Task Force (USPSTF) ${ }^{9}$ and the US MultiSociety Taskforce. ${ }^{10}$ The ACS recommendation was informed by microsimulation modeling that estimated CRC cases and deaths averted and the number of colonoscopies required to gain a life-year. ${ }^{11}$ Economic outcomes and the potential trade-offs at the population level in allocating screening resources to younger persons were not considered in the modeling for the $\mathrm{ACS}^{11}$ or in the ACS guideline. ${ }^{8}$

Death from CRC in a young person is devastating. However, the vast majority of CRCs occur after age 50 years. ${ }^{12}$ The annual colon and rectal cancer incidence rates in 50-84-yearolds range from approximately 2- to 13 -fold and 2- to 5-fold higher than incidence rates in $40-49$-year-olds, respectively. ${ }^{1}$ Only approximately $62 \%$ of persons older than 50 years currently participate in CRC screening in the United States. ${ }^{13,14}$ 
Since the ACS recommendation was issued, intense discussion has ensued regarding the potential benefits, liabilities, and costs of implementing it at a national level. ${ }^{15-17}$ The United States does not have a national CRC screening program that is formally constrained by a fixed budget or a cap on colonoscopy supply. Nonetheless, health care systems, communities, clinical practices, and advocacy organizations are grappling with resource allocation challenges: should they now focus on delivering CRC screening to 45-49-yearolds, should they concentrate on the large fraction of screening-eligible older people who are not currently being screened, or can they do both?

Our aims were to estimate the cost effectiveness and national impact of beginning CRC screening at age 45 instead of 50 years and to contrast the effect of allocating screening resources to younger vs older and higher-risk persons.

\section{Methods}

\section{Study Overview}

We first compared the clinical predictions of our validated decision analytic model of CRC screening ${ }^{18,19}$ to those of the model that informed the ACS recommendation. The high concordance between both models' predictions suggests that our findings are relevant to the ACS recommendation. We then examined the cost effectiveness of earlier initiation of CRC screening. Next, we explored the potential clinical and economic trade-offs when allocating screening resources to younger vs older unscreened persons or higher-risk subgroups, such as those with abnormal fecal immunochemical testing (FIT) results who fail to undergo prompt colonoscopy. Finally, we conducted extensive sensitivity analyses.

\section{Decision Analytic Model}

The details and validation of our model against randomized controlled trials of fecal occult blood testing ${ }^{20,21}$ and sigmoidoscopy ${ }^{22-24}$ are detailed in previous publications ${ }^{18,19}$ (see Supplementary Material). The model is constructed in TreeAge Pro (TreeAge Software, Williamstown, MA), and Excel 2018 (Microsoft, Redmond, WA) is used for analyses. The close match between our model's current national estimates and observational data ${ }^{12,25,26}$ served as further model validation.

The model reproduces the natural history of CRC precursors and CRC in the general US population without screening (see details in the Supplementary Material including inputs in Supplementary Table 1 and model schematic in Supplementary Figure 1). Persons transition between health states of normal, small polyp, large polyp, localized, regional or disseminated CRC, and death in 1-year cycles. Screening and post-polypectomy surveillance are superimposed on the natural history module, accounting for test performance characteristics, complications, and costs. Age-specific non-CRC mortality is considered. Persons are followed up until age 100 years or death.

\section{CRC in the Population}

CRC risk in our original model is calibrated to 1990-1994 Surveillance, Epidemiology and End Results (SEER) data, which preceded the widespread use of CRC screening. We 
recalibrated the model to reflect the increases in CRC incidence under age 50 years for each 5 -year birth cohort over recent decades (see Supplementary Materials). ${ }^{12}$ Because of decreasing CRC incidence at older ages over time, which is likely to be related in large part to screening, (Supplementary Figure 2) it is not possible to obtain the age-specific natural history CRC risk (ie, with no screening) at older ages in more recent years directly from SEER data. We assumed that the relative risks of CRC derived for younger persons (ie, without widespread screening) apply to the age cohorts over time if they have no screening at older ages, ${ }^{1}$ as was assumed in the modeling for the ACS. ${ }^{11}$ Because this is a fundamental assumption, we tested its impact in sensitivity analyses.

To reflect changes in CRC relative risk over recent decades, incidence rate ratios (IRRs) were calculated for today's 40-45-year-olds and other age cohorts relative to the 1990-1994 data to which our original model was calibrated, as was done in the modeling for the ACS (see Supplementary Material). ${ }^{11}$ For example, in 1990-1994, the annual CRC incidence was 11.9-13.4/100,000 in 40-44-year-olds, with an average of 12.7/100,000, and 22.2$26.1 / 100,000$ in 45-49-year-olds, with an average of 24.7/100,000. ${ }^{12}$ In the most recent SEER data from 2015, the annual CRC incidence was 19.6/100,000 in 40-44-year-olds (the cohort of "contemporary 45-49-year-olds" who will be 45-49 years old in 2020) and $33.4 / 100,000$, in $45-49$-year-olds. ${ }^{12}$ We therefore calculated that contemporary 45-49-yearolds have a CRC IRR of 1.54 (19.6/12.7) and that contemporary 50-54-year-olds have a CRC IRR of 1.35 (33.4/24.7), compared with our original model calibration. ${ }^{12}$ Our calculated IRR for contemporary 45-49-year-olds differs slightly from the value derived in the modeling for the ACS, which was $1.591,{ }^{11}$ but that model's original calibration was to data from 1975-1979, so it is not surprising that our multipliers are similar but not identical. The IRRs we calculated for the various age cohorts (Supplementary Table 2) are consistent with the values in the recent analysis of Siegel et $\mathrm{al}^{1}$ that highlighted the birth cohort effect in CRC risk, with progressively increasing risk in recent decades. Because CRC IRR was expected to exert substantial influence on the results and conclusions, we varied it extensively in sensitivity analyses.

It is possible that the overall increase in CRC relative risk in the population may be attributable to a substantial increase in risk among a subpopulation (eg, with environmental risk factors, including obesity) and no change in risk among others. Although it is not clear at present how to identify this subgroup with confidence, we considered the possibility of identifying a subgroup for earlier screening in sensitivity analyses, as will be described.

\section{Screening and Surveillance Strategies}

We focused on colonoscopy and FIT, the strategies recommended by the $\mathrm{ACS}^{8}$ and USPSTF$^{9}$ that account for the vast majority of CRC screenings in the United States. ${ }^{13,14}$ Because approximately $70 \%$ of CRCs in younger persons are potentially within the reach of sigmoidoscopy, ${ }^{12}$ sigmoidoscopy at age 45 years has been proposed as a potential approach. Thus, although this strategy is not included in any guideline currently, we also modeled 1time sigmoidoscopy at age 45 years, with transition to colonoscopy every 10 years or annual FIT at age 50 years. In addition, a hybrid strategy of annual FIT at earlier ages and screening colonoscopy at older ages has emerged as an attractive strategy in previous decision 
analyses. ${ }^{27,28} \mathrm{We}$ also explored annual FIT at ages $45-49$ years, with transition to colonoscopy every 10 years at age 50 years.

The principal comparisons involved screening at ages $45-75$ vs $50-75$ years, with postpolypectomy surveillance through age 80 years. Surveillance was performed 3 years after removal of large polyps and 5 years after removal of small polyps. ${ }^{29}$ Test sensitivity and specificity were assumed to be the same at all ages.

\section{Cost Inputs}

Base case cost inputs were derived from 2018 Centers for Medicare and Medicaid Services reimbursement rates ${ }^{30-32}$ and estimated CRC care $\operatorname{costs}^{33}$ for persons $\ 65$ years old. There is scant literature on commercial insurance payments (as opposed to charges) for CRC screening tests, including colonoscopy and CRC care. We recently analyzed commercial payment rates for colorectal tests in persons ages 50-64 years in the Truven MarketScan Databases. ${ }^{34}$ Our results informed our inputs for testing costs in persons at $<65$ years old accounting for colonoscopy site of service 33,34 and were updated to 2018 dollars by using the medical care component of the consumer price index (Supplementary Table 1). Based on the mean ratio of 1.35 for commercial to Medicare payment rates for all colorectal tests in our previous study, ${ }^{34}$ we assumed CRC care and complication costs for persons ages 45-64 years that were 1.35 -fold those of persons $\geq 65$ years old. ${ }^{19}$ Because the costs of screening and CRC care under commercial insurance at ages $<65$ years could be important determinants of the relative cost effectiveness of competing screening strategies, we performed sensitivity analyses using cost inputs based on other recent studies (see Supplementary Material). ${ }^{35-37}$

\section{Clinical and Economic Outcomes, Perspective, and Cost-Effectiveness Analyses}

The principal model outputs were CRC cases and deaths, quality-adjusted life-years (QALYs), costs, and resources demand in cohorts of 1000 persons. ${ }^{38}$ Future QALYs and costs were discounted by $3 \%$ annually. Health state utilities for CRC by stage were applied for 5 years after CRC diagnosis. Analyses were performed by using a health sector perspective. ${ }^{38}$

\section{Comparison With Model Used to Inform the ACS Recommendations}

To test the concordance between our model's clinical estimates and those of the model used to inform the ACS recommendations, we performed analyses without discounting and with post-polypectomy surveillance performed indefinitely, as performed in the ACS model (see Supplementary Materials). ${ }^{11}$

\section{Cost Effectiveness of Initiating Screening at Age 45 Years}

The cost effectiveness of initiating screening at age 45 vs 50 years was first estimated independent of potential trade-offs or national impact, and the required resources were quantified. Cost effectiveness was expressed as incremental cost/QALY gained. 


\section{Potential Trade-Offs}

We explored the clinical and economic impact of allocating the resources that would be required to screen 45 -year-olds to instead screen 55-year-olds or 65 -year-olds who remain unscreened today, sustaining screening through age 75 years. We also examined the impact of allocating these resources to increasing colonoscopy completion among persons with abnormal FIT results. ${ }^{39}$

\section{National Projections}

National estimates were generated for clinical and economic outcomes and resource demands over the next 5 years under various scenarios of screening participation, accounting for age cohort-specific CRC relative risks, historical screening participation patterns, and population size (see Supplementary Materials). The scenarios included continued screening at current rates, a 5-year shift of current screening rates from age 50 years to younger ages (ie, beginning at age 45 years), beginning screening at age 45 years with participation rates extrapolated from current rates at older ages and without increases in participation rates at older ages, and achieving the aspirational goal of sustained $80 \%$ participation rates beginning at age 45 or 50 years.

\section{Sensitivity Analyses}

Sensitivity analyses examined all model inputs. We hypothesized a priori that the most critical variables might be CRC risk, screening and CRC treatment costs, screening and surveillance time horizons, and prognosis of CRC diagnosed at ages 45-49 years.

There is intense interest in the potential acceptability of extending the surveillance interval after removal of 1-2 small adenomas from 5 years to 10 years, a research question being addressed by the European Polyp Surveillance (ie, EPoS) trial. ${ }^{40}$ A reduction in the demand for surveillance colonoscopy could potentially compensate for increased use of screening colonoscopy at ages 45-49 years. A comprehensive analysis of the clinical and economic impact of extending this surveillance interval requires recalibration and validation of a model's surveillance module to reflect all recently published information on surveillance, which was beyond the scope of the current analysis. Nonetheless, approximate estimates of the impact on resource demands are informative. Thus, we performed an exploratory analysis of total colonoscopy demand with a screening colonoscopy strategy in which we extended the surveillance interval after removal of a small polyp to 10 years instead of 5 years.

In an exploratory sensitivity analysis, we assumed that the overall increase in CRC relative risk was attributable to an increase in risk among $30 \%$ of people, who could be identified with confidence as being at higher risk. To achieve an overall CRC IRR of 1.54 in the population, this $30 \%$ would need to experience a CRC IRR of 2.8 , with the remaining $70 \%$ retaining a CRC IRR of 1.0. We modeled initiating screening colonoscopy at age 45 years in this higher-risk subgroup while retaining screening colonoscopy initiation at age 50 years in the rest of the population or initiating screening colonoscopy at age 45 years in all. 


\section{Results}

\section{Comparison With Model Used to Inform the ACS Recommendations}

The model's estimates for averted CRC cases and deaths, incremental screening test demand, and life-years gained with screening at age 45 instead of 50 years were highly concordant with those used to inform the ACS recommendations ${ }^{11}$ (Supplementary Tables 3 and 4).

\section{Base Case: Cost-Effectiveness of Screening Initiation at Age 45 vs 50 Years}

The base case clinical and economic outcomes for screening through age 75 years are shown in Table 1, focusing on the comparisons between the new paradigm of screening initiation at age 45 years vs the existing paradigm of screening initiation at age 50 years. Screening colonoscopy initiation at age 45 instead of 50 years averted 4 CRCs and 2 CRC deaths and gained 14.4 discounted QALYs per 1000 persons, but it required 758 additional colonoscopies and cost $\$ 33,900 / \mathrm{QALY}$ gained. FIT initiation at age 45 instead of 50 years averted 4 CRCs and one CRC death and gained 14.0 discounted QALYs per 1000 persons, but it required 267 additional colonoscopies and 3242 additional stool tests and cost $\$ 7700$ / QALY gained. Most of the benefits of early screening initiation were observed at ages 45-54 years (Supplementary Figure 3).

One-time sigmoidoscopy at age 45 years followed by colonoscopy or FIT screening starting at age 50 years achieved nearly the same clinical benefits as initiating colonoscopy or FIT at age 45 years, but at slightly higher overall costs due to sigmoidoscopy's negligible benefit in the proximal colon. Similarly, annual FIT at ages 45-49 years with transition to colonoscopy every 10 years at age 50 years achieved nearly the same clinical benefits as initiating colonoscopy at age 45 years, and it was highly cost effective compared with initiating colonoscopy at age 50 years (Table 1 ).

\section{Potential Trade-Offs: Alternative Allocation of Colonoscopy Resources}

The clinical and economic consequences of allocating colonoscopy resources to initiating colonoscopy screening at age 45 years vs focusing on groups with higher CRC risk are illustrated in Table 2 (details in Supplementary Table 5). The incremental 758 colonoscopies required to screen 1000 persons beginning at age 45 instead of 50 years could instead be used to initiate and sustain screening through age 75 years in 231 currently unscreened 55year-olds or 342 currently unscreened 65 -year-olds. These alternative allocations yielded substantially greater clinical benefits than initiating colonoscopy screening at age 45 years: 13-14 CRC cases averted, 6-7 CRC deaths averted, and 27-28 discounted QALYs gained (Table 2). In contrast to the increase in total costs observed with screening initiation at age 45 instead of 50 years, these alternative allocations resulted in net savings of $\$ 163,700$ $\$ 445,800$ (Table 2). Allocating colonoscopies to improve follow-up rates after abnormal FIT results also yielded substantially greater benefits than initiating colonoscopy screening at age 45 years (Table 2). 


\section{Projected National Clinical and Economic Impact and Resource Demands}

The clinical and economic consequences of alternative population-wide screening participation scenarios over the next 5 years in the United States are presented in Figure 1. If current age-specific screening participation patterns were shifted by 5 years to younger ages (Figure 1, scenario B), 29,400 CRC cases and 11,100 CRC deaths could be averted over the next 5 years, at an incremental cost of $\$ 10.4$ billion and requiring 10.7 million additional colonoscopies. Substantially lower clinical and economic impact would be observed if 45 49-year-olds participated in screening at a rate extrapolated from current rates at older ages and without changes to current screening participation rates at older ages (Figure 1, scenario C). By comparison, achieving the aspirational goal of $80 \%$ screening participation beginning at age 50 years, without screening initiation at age 45 years, could avert 2.6-fold more CRC cases and 2.9-fold more CRC deaths at approximately one third the incremental cost and with the need for $13 \%$ more additional colonoscopies, compared with shifting current agespecific participation rates to 5 years earlier (Figure 1, scenario E). More substantial clinical benefits, but at higher costs and with higher colonoscopy demand, would be realized with $80 \%$ screening participation beginning at age 45 years (Figure 1, scenario D).

\section{Sensitivity Analyses}

The results were highly sensitive to the level of CRC risk in the population (Figure 2) and to the costs of colonoscopy and CRC care but not to variation in screening and surveillance time horizons, survival with CRC diagnosed at ages 45-49 years, colonoscopy or FIT test performance characteristics, colonoscopy complication rates, or CRC health state utilities (Table 3 and Supplementary Table 6). At CRC relative risks of 0.75 and 0.50 compared with the original model calibration, which are approximately one half and one third, respectively, of the risk assumed for today's 45-49-year-olds in the base case, initiating colonoscopy screening at age 45 vs 50 years cost, respectively, $\$ 95,900 /$ QALY gained and $\$ 162,800$ / QALY gained. Early initiation of FIT screening remained relatively cost effective even at low levels of CRC risk (Figure 2 and Table 3). When colonoscopy costs were increased or $\mathrm{CRC}$ care costs were decreased within plausible ranges, the incremental cost effectiveness of screening at age 45 years remained well below $\$ 100,000 /$ Q ALY gained (Supplementary Table 6).

With surveillance after small polyp removal at 10 years, screening colonoscopy beginning at age 45 or 50 years required 3,679 or 2,890 colonoscopies, respectively, over a lifetime in 1000 persons. These estimates reflect $23 \%$ and $28 \%$ reductions in colonoscopy demand when compared with the strategies based on surveillance after small polyp removal at 5 years (Table 1).

When we assumed that CRC risk increased only in a subpopulation that could be identified with confidence as being at higher risk, initiating screening colonoscopy in this population at age 45 years while retaining screening colonoscopy initiation in the rest of the population at age 50 years cost $\$ 10,700 /$ QALY gained compared with initiating screening colonoscopy in all at age 50 years. Initiating screening colonoscopy in all at age 45 years cost $\$ 64,900 /$ QALY gained compared with initiating screening colonoscopy at age 45 years only in the subpopulation identified as being at higher risk and in all others at age 50 years. 


\section{Discussion}

The ACS qualified recommendation to begin average-risk CRC screening at age 45 years 8 has profound implications, given that 21 million Americans are 45-49 years old today and that 4 million or more are anticipated to turn 45 every year in the near future. ${ }^{26}$ The ACS recommendation raises questions about implementation, insurance coverage, national screening capacity, and the optimal strategies to reduce the population burden of CRC. ${ }^{8}$

Since the ACS announcement, intense discussion has ensued. ${ }^{15-17}$ Common themes include the following: despite the rising incidence of CRC in younger persons, the absolute risks remain substantially lower than in older persons; evidence that screening benefits younger age groups is scant; uncertainty remains regarding the persistence of CRC risk elevation as cohorts age; low-risk younger persons may be the ones who take up earlier screening; modeling that assumes $100 \%$ compliance without consideration of costs has limitations; and, perhaps most importantly, questions remain regarding the balance among benefits, liabilities, and costs at a national level. ${ }^{15-17}$

Our results suggest that, given the rising CRC incidence in younger people, initiating CRC screening at age 45 years is economically attractive (ie, cost effective) across a wide range of assumptions (Table 3 and Supplementary Table 6). Most of the benefits of early screening initiation were observed at ages 45-54 years, as was hypothesized by the ACS. ${ }^{8}$ Our conclusions remain robust even if the relative elevation in CRC risk compared with historical reference groups disappears after age 50 years (Table 3) - that is, without assuming that the risk elevation persists for a lifetime. However, if CRC risk in the 45-49year-olds who are actually screened were appreciably lower than the birth-cohort average, the endoscopy-based strategies would become costly with respect to their benefits (Table 3 and Figure 2). Thus, if predominantly healthier, lower-risk persons self-select into earlier screening, or if such persons are selected by health systems due to convenience, insurance status, access, or financial motivations, then the costs to payers could be high relative to the benefits.

The broader societal perspective is arguably more important than the narrower costeffectiveness question. Our analyses show that given the choice over how to deploy a fixed number of colonoscopies, the clinical benefits would be far greater if screening were performed among the $44 \%$ of 55 -year-olds and $37 \%$ of 65 -year-olds who remain unscreened, 13,14 or if colonoscopies were allocated to improve colonoscopy completion after abnormal FIT, ${ }^{39}$ than if average-risk screening were initiated at age 45 years (Table 2). The same conclusion would be expected if colonoscopies could be directed to high-risk persons identified with confidence by risk-prediction models or biomarkers, including hybrid models that consider environmental and genetic factors, ${ }^{17,41}$ instead of average-risk 45 -year-olds. Furthermore, our results suggest that focusing on older and higher-risk persons would yield substantial net savings, due to the averted CRC treatment costs (Table 2). These recovered financial resources could potentially be used to develop outreach and navigation programs to improve screening participation and follow-up after abnormal FIT results. ${ }^{42-47}$ 
The crucial question is whether we can "do it all" - that is, initiate screening earlier and simultaneously serve older and higher-risk groups, or whether we face constraints and, thus, choices that will be made explicitly or implicitly. Colonoscopy capacity is a concern. Although it is possible that ample colonoscopy capacity exists in the United States to support $80 \%$ screening participation even starting at age 45 years (Figure 1) ${ }^{48}$ it is not clear that merely offering screening will overcome geographic, insurance, and additional systemlevel and patient-level barriers that underlie current disparities. ${ }^{49}$ Even if a shift in the screening initiation age were universally endorsed, barriers to screening would remain for many 45-49-year-olds. Similarly, efforts to increase follow-up colonoscopy rates after abnormal FIT results must contend with substantial barriers at the patient, provider, and system levels. ${ }^{39}$

There is evidence of suboptimal use of surveillance colonoscopy resources, ${ }^{50}$ and there is intense interest in the possibility of lengthening the surveillance interval after removal of 12 small adenomas to 10 years. ${ }^{40}$ In-depth analyses of the potential redeployment of colonoscopy resources across the entire spectrum of screening and surveillance was beyond the scope of this study. However, our exploratory analysis suggests that such a change in surveillance interval could diminish the total demand of colonoscopy in a screening colonoscopy-based program by $23 \%-28 \%$. This capacity could potentially be redeployed to screening in both contemporary average-risk younger cohorts and higher-risk older cohorts.

The ultimate impact of a change in screening policy will depend on the participation patterns that are achieved. Screening has contributed significantly to the declining CRC incidence and mortality in older Americans. Substantial further reductions could be achieved if $80 \%$ screening participation were achieved beginning at age 50 years, and even greater reductions might be realized if this were achieved beginning at age 45 years (Figure 1). However, the latter would require substantial incremental resources over those expended today: approximately $\$ 1.4$ billion additional annually and a $20 \%$ increase over the approximate 15 million colonoscopies currently performed annually 48 (Figure 1).

In addition to the impact that increasing $\mathrm{CRC}$ risk has on the optimal screening initiation age, it also affects the cost effectiveness of screening initiation at age 50 years. In our base case, colonoscopy every 10 years starting at age 50 years was both more effective and less costly (ie, dominant) compared with no screening (Table 1). In previous studies, including ours, colonoscopy has usually emerged as highly cost effective, but not cost saving, compared with no screening. This shift in the current analysis from highly cost effective to cost saving is attributable directly to the higher assumed CRC risk in contemporary 45-49year-olds (IRR,1.54), in contrast with previous analyses that based CRC risk on SEER data from decades ago. For instance, in the current analysis, at a CRC IRR of 1.35 (the CRC risk that we calculated for contemporary 50-54-year-olds), colonoscopy every 10 years starting at age 50 years was estimated to be cost-saving, but at an IRR of 1.18 (the CRC risk that we calculated for contemporary 55-59-year-olds), it was estimated to be highly cost effective but no longer cost saving (see Supplementary Materials).

The concordance between our model's clinical estimates and those of the model used to inform the ACS recommendations, ${ }^{8,11}$ as well as national CRC incidence and mortality data, 
$12,25,26$ provides confidence in our national projections. We explored questions that, to our knowledge, have not been previously addressed, ${ }^{8,11}$ including the cost effectiveness of the new ACS recommendation, its implications at the national level, the trade-offs compared with focusing resources on older unscreened persons, and the impact of hybrid strategies with sigmoidoscopy or FIT at earlier ages with transition to FIT or colonoscopy at older ages.

The limitations of our study include the fact that it remains a modeling exercise, but we attempted to account for the critical epidemiologic issues. Consideration of risk stratification with prediction models or biomarkers was beyond the scope of the current study. Colonoscopy that is performed to evaluate symptoms can also serve for screening, and counting such colonoscopy costs as related to screening could overestimate the total budget impact of screening. It was beyond the scope of this analysis to examine alternative health care expenditures that could be considered instead of lowering the CRC screening initiation age (eg, prenatal care, immunizations, costly medications).

CRC screening is a priority endorsed by the USPSTF as a grade A recommendation. Our results suggest that lowering the $\mathrm{CRC}$ screening initiation age from 50 to 45 years is likely to be cost effective. However, whether this is desirable as national policy depends on whether it can be instituted without displacing efforts to achieve high screening participation rates in older or higher-risk persons and whether society is willing to bear the incremental costs. Improving screening rates in older or higher-risk persons or ensuring colonoscopy completion after abnormal results on FIT or other noninvasive tests would provide substantially greater benefits than initiating average-risk screening at age 45 years. Research to determine the yield of average-risk CRC screening beginning at age 45 years and its impact on screening participation at older ages will be invaluable to inform future practice guidelines.

\section{Supplementary Material}

Refer to Web version on PubMed Central for supplementary material.

\section{Acknowledgments}

Author contributions: Study concept and design: Uri Ladabaum, Ajitha Mannalithara, Samir Gupta, Reinier G.S. Meester, Robert E. Schoen; acquisition of data: Uri Ladabaum, Ajitha Mannalithara; analysis and interpretation of data: Uri Ladabaum, Ajitha Mannalithara, Reinier G.S. Meester; drafting of the manuscript: Uri Ladabaum, Ajitha Mannalithara, Samir Gupta, Reinier G.S. Meester, Robert E. Schoen; critical revision of the manuscript for important intellectual content: Uri Ladabaum, Ajitha Mannalithara, Samir Gupta, Reinier G.S. Meester, RS; statistical analysis: Uri Ladabaum, Ajitha Mannalithara, Reinier G.S. Meester; technical, or material support: Ajitha Mannalithara; study supervision: Uri Ladabaum.

\section{Abbreviations used in this paper:}

$\begin{array}{ll}\text { ACS } & \text { American Cancer Society } \\ \text { CRC } & \text { colorectal cancer } \\ \text { FIT } & \text { fecal immunochemical test }\end{array}$




$\begin{array}{ll}\text { IRR } & \text { incidence rate ratio } \\ \text { QALY } & \text { quality-adjusted life-year } \\ \text { SEER } & \text { Surveillance, Epidemiology and End Results } \\ \text { USPSTF } & \text { US Preventive Services Task Force }\end{array}$

\section{References}

1. Siegel RL, Fedewa SA, Anderson WF, et al. Colorectal cancer incidence patterns in the United States, 1974-2013. J Natl Cancer Inst 2017:109.

2. Hewitson P, Glasziou P, Watson E, et al. Cochrane systematic review of colorectal cancer screening using the fecal occult blood test (hemoccult): an update. Am J Gastroenterol 2008;103:1541-1549. [PubMed: 18479499]

3. Elmunzer BJ, Hayward RA, Schoenfeld PS, et al. Effect of flexible sigmoidoscopy-based screening on incidence and mortality of colorectal cancer: a systematic review and meta-analysis of randomized controlled trials. PLoS Med 2012;9:e1001352. [PubMed: 23226108]

4. Nishihara R, Wu K, Lochhead P, et al. Long-term colorectal-cancer incidence and mortality after lower endoscopy. N Engl J Med 2013;369:1095-1105. [PubMed: 24047059]

5. Zauber AG, Winawer SJ, O'Brien MJ, et al. Colonoscopic polypectomy and long-term prevention of colorectal-cancer deaths. N Engl J Med 2012;366:687-696. [PubMed: 22356322]

6. Levin TR, Corley DA, Jensen CD, et al. Effects of organized colorectal cancer screening on cancer incidence and mortality in a large, community-based population. Gastroenterology 2018;155:13831391. [PubMed: 30031768]

7. Edwards BK, Ward E, Kohler BA, et al. Annual report to the nation on the status of cancer, 19752006, featuring colorectal cancer trends and impact of interventions (risk factors, screening, and treatment) to reduce future rates. Cancer 2010;116:544-573. [PubMed: 19998273]

8. Wolf AMD, Fontham ETH, Church TR, et al. Colorectal cancer screening for average-risk adults: 2018 guideline update from the American Cancer Society. CA Cancer J Clin 2018;68:250-281. [PubMed: 29846947]

9. Bibbins-Domingo K, Grossman DC, Curry SJ, et al. Screening for colorectal cancer: US Preventive Services Task Force recommendation statement. JAMA 2016; 315:2564-2575. [PubMed: 27304597]

10. Rex DK, Boland CR, Dominitz JA, et al. Colorectal cancer screening: recommendations for physicians and patients from the U.S. Multi-Society Task Force on Colorectal Cancer. Gastroenterology 2017;153:307-323. [PubMed: 28600072]

11. Peterse EFP, Meester RGS, Siegel RL, et al. The impact of the rising colorectal cancer incidence in young adults on the optimal age to start screening: microsimulation analysis I to inform the American Cancer Society colorectal cancer screening guideline. Cancer 2018;124:2964-2973. [PubMed: 29846933]

12. Surveillance, Epidemiology, and End Results Program. https://seer.cancer.gov. Accessed September 25, 2018.

13. de Moor JS, Cohen RA, Shapiro JA, et al. Colorectal cancer screening in the United States: trends from 2008 to 2015 and variation by health insurance coverage. Prev Med 2018;112:199-206. [PubMed: 29729288]

14. Sauer AG, Liu B, Siegel RL, et al. Comparing cancer screening estimates: Behavioral Risk Factor Surveillance System and National Health Interview Survey. Prev Med 2018;106:94-100. [PubMed: 29079098]

15. Bretthauer M, Kalager M, Weinberg DS. From colorectal cancer screening guidelines to headlines: Beware! Ann Intern Med 2018;169:405-406. [PubMed: 29987330]

16. Liang PS, Allison J, Ladabaum U, et al. Potential intended and unintended consequences of recommending initiation of colorectal cancer screening at age 45 years. Gastroenterology 2018;155:950-954. [PubMed: 30138614] 
17. Imperiale TF, Kahi CJ, Rex DK. Lowering the starting age for colorectal cancer screening to 45 years: who will come ... and should they? Clin Gastroenterol Hepatol 2018;16:1541-1544. [PubMed: 30114484]

18. Ladabaum U, Song K. Projected national impact of colorectal cancer screening on clinical and economic outcomes and health services demand. Gastroenterology 2005;129:1151-1162. [PubMed: 16230069]

19. Ladabaum U, Mannalithara A. comparative effectiveness and cost effectiveness of a multitarget stool DNA test to screen for colorectal neoplasia. Gastroenterology 2016; 151:427-439. [PubMed: 27311556]

20. Mandel JS, Bond JH, Church TR, et al. Reducing mortality from colorectal cancer by screening for fecal occult blood. Minnesota Colon Cancer Control Study. N Engl J Med 1993;328:1365-1371. [PubMed: 8474513]

21. Mandel JS, Church TR, Bond JH, et al. The effect of fecal occult-blood screening on the incidence of colorectal cancer. N Engl J Med 2000;343:1603-1607. [PubMed: 11096167]

22. Atkin WS, Edwards R, Kralj-Hans I, et al. Once-only flexible sigmoidoscopy screening in prevention of colorectal cancer: a multicentre randomised controlled trial. Lancet 2010;375:16241633. [PubMed: 20430429]

23. Segnan N, Armaroli P, Bonelli L, et al. Once-only sigmoidoscopy in colorectal cancer screening: follow-up findings of the Italian Randomized Controlled Trial-- SCORE. J Natl Cancer Inst 2011;103:1310-1322. [PubMed: 21852264]

24. Schoen RE, Pinsky PF, Weissfeld JL, et al. Colorectal-cancer incidence and mortality with screening flexible sigmoidoscopy. N Engl J Med 2012;366:2345-2357. [PubMed: 22612596]

25. Siegel RL, Miller KD, Jemal A. Cancer statistics, 2018. CA Cancer J Clin 2018;68:7-30. [PubMed: 29313949]

26. United States Census Bureau. https://www.census.gov. Accessed September 25, 2018.

27. Dinh T, Ladabaum U, Alperin P, et al. Health benefits and cost-effectiveness of a hybrid screening strategy for colorectal cancer. Clin Gastroenterol Hepatol 2013; 11:1158-1166. [PubMed: 23542330]

28. Ladabaum U, Alvarez-Osorio L, Rosch T, et al. Cost-effectiveness of colorectal cancer screening in Germany: current endoscopic and fecal testing strategies versus plasma methylated Septin 9 DNA. Endosc Int Open 2014;2:e96-e104. [PubMed: 26135268]

29. Lieberman DA, Rex DK, Winawer SJ, et al. Guidelines for colonoscopy surveillance after screening and polypectomy: a consensus update by the US Multi-Society Task Force on Colorectal Cancer. Gastroenterology 2012;143:844-857. [PubMed: 22763141]

30. Centers for Medicare \& Medicaid Services. Clinical laboratory fee schedule. http://www.cms.gov/ Medicare/Medicare-Fee-for-Service-Payment/ClinicalLabFeeSched/. Updated February 27, 2019. Accessed June 27, 2018.

31. Centers for Medicare \& Medicaid Services. Physician fee schedule. http://www.cms.gov/Medicare/ Medicare-Fee-for-Service-Payment/PhysicianFeeSched/. Updated May 8, 2019. Accessed June 27, 2018.

32. Centers for Medicare \& Medicaid Services. Acute Inpa-tient PPS. http://www.cms.gov/Medicare/ Medicare-Fee-for-Service-Payment/AcuteInpatientPPS/. Updated March 8, 2019. Accessed June 27, 2018.

33. Zauber AG, Lansdorp-Vogelaar I, Wilschut J, et al. Cost-effectiveness of DNA stool testing to screen for colorectal cancer. https://www.cms.gov/Medicare/Coverage/DeterminationProcess/ downloads/id52TA.pdf. Published December 20, 2007.

34. Ladabaum U, Levin Z, Mannalithara A, et al. Colorectal testing utilization and payments in a large cohort of commercially insured US adults. Am J Gastroenterol 2014;109:1513-1525. [PubMed: 24980877]

35. Fitch K, Pyenson B, Blumen H, et al. The value of colonoscopic colorectal cancer screening of adults aged 50 to 64. Am J Manag Care 2015;21:e430-e438. [PubMed: 26295271]

36. Pyenson B, Scammell C, Broulette J. Costs and repeat rates associated with colonoscopy observed in medical claims for commercial and Medicare populations. BMC Health Serv Res 2014;14:92. [PubMed: 24572047] 
37. Seal BS, Sullivan SD, Ramsey S, et al. Medical costs associated with use of systemic therapy in adults with colorectal cancer. J Manag Care Pharm 2013;19:461-467. [PubMed: 23806060]

38. Sanders GD, Neumann PJ, Basu A, et al. Recommendations for conduct, methodological practices, and reporting of cost-effectiveness analyses: second Panel on Cost-Effectiveness in Health and Medicine. JAMA 2016;316:1093-1103. [PubMed: 27623463]

39. Martin J, Halm EA, Tiro JA, et al. Reasons for lack of diagnostic colonoscopy after positive result on fecal immunochemical test in a safety-net health system. Am J Med 2017;130:93.e1-93.e7.

40. Jover R, Bretthauer M, Dekker E, et al. Rationale and design of the European Polyp Surveillance (EPoS) trials. Endoscopy 2016;48:571-578. [PubMed: 27042931]

41. Jeon J, Du M, Schoen RE, et al. Determining risk of colorectal cancer and starting age of screening based on lifestyle, environmental, and genetic factors. Gastroenterology 2018;154:2152-2164.e19. [PubMed: 29458155]

42. Subramanian S, Tangka FK, Hoover S, et al. Costs of planning and implementing the CDC's Colorectal Cancer Screening Demonstration Program. Cancer 2013;119-(Suppl 15):2855-2862. [PubMed: 23868480]

43. Subramanian S, Tangka FK, Hoover S, et al. Clinical and programmatic costs of implementing colorectal cancer screening: evaluation of five programs. Eval Program Plann 2011;34:147-153. [PubMed: 21036399]

44. Chen LA, Santos S, Jandorf L, et al. A program to enhance completion of screening colonoscopy among urban minorities. Clin Gastroenterol Hepatol 2008;6:443-450. [PubMed: 18304882]

45. Jandorf L, Braschi C, Ernstoff E, et al. Culturally targeted patient navigation for increasing african americans' adherence to screening colonoscopy: a randomized clinical trial. Cancer Epidemiol Biomarkers Prev 2013; 22:1577-1587. [PubMed: 23753039]

46. Elkin EB, Shapiro E, Snow JG, et al. The economic impact of a patient navigator program to increase screening colonoscopy. Cancer 2012;118:5982-5988. [PubMed: 22605672]

47. Ladabaum U, Mannalithara A, Jandorf L, et al. Cost-effectiveness of patient navigation to increase adherence with screening colonoscopy among minority individuals. Cancer 2015;121:1088-1097. [PubMed: 25492455]

48. Joseph DA, Meester RG, Zauber AG, et al. Colorectal cancer screening: Estimated future colonoscopy need and current volume and capacity. Cancer 2016; 122:2479-2486. [PubMed: 27200481]

49. Gupta S, Sussman DA, Doubeni CA, et al. Challenges and possible solutions to colorectal cancer screening for the underserved. J Natl Cancer Inst 2014;106(4):dju032. [PubMed: 24681602]

50. Schoen RE, Pinsky PF, Weissfeld JL, et al. Utilization of surveillance colonoscopy in community practice. Gastroenterology 2010;138:73-81. [PubMed: 19818779] 


\begin{tabular}{|c|c|c|c|}
\hline & $\begin{array}{l}\text { Scenario A: } \\
\text { Current age-specific } \\
\text { screening participation } \\
\text { patterns in the U.S. }{ }^{\star \star}\end{array}$ & $\begin{array}{l}\text { Scenario B: } \\
\text { Begin screening at age } 45 \\
\text { (shift current age-band- } \\
\text { specific participation patterns } \\
\text { by } 5 \text { years to younger ages) }\end{array}$ & $\begin{array}{l}\text { Scenario C: } \\
\text { Begin screening at age } 45 \\
\text { (extrapolate participation } \\
\text { rate at age } 45 \text { based on } \\
\text { current participation } \\
\text { patterns, without change in } \\
\text { participation at older ages) }\end{array}$ \\
\hline $\begin{array}{l}\text { Age-specific screening } \\
\text { participation rates with } \\
\text { colonoscopy (in white) or } \\
\text { fecal immunochemical test (in } \\
\text { black) }\end{array}$ & $\left.\begin{array}{c}100 \% \\
80 \% \\
60 \% \\
{ }^{60 \%}- \\
20 \% \\
-7\end{array}\right]=7=$ & ${ }_{200 \%}^{100 \%}-1=$ & 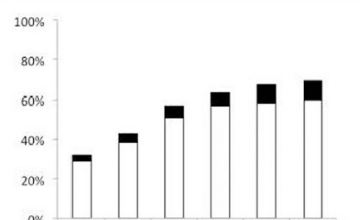 \\
\hline & $\begin{array}{llllll}45-49 & 50.54 & 55-59 & 60.64 & 65.69 & 70-75\end{array}$ & $\begin{array}{lllllll}0 \% & 45.49 & 50.54 & 55.59 & 60.64 & 65-69 & 70-75\end{array}$ & $\begin{array}{llllllll}0 \% & 45-49 & 50.54 & 55-59 & 60.64 & 65.69 & 70.75\end{array}$ \\
\hline Colorectal cancer cases & 696,700 & $\begin{array}{c}667,300 \\
(\downarrow 29,400) \\
\end{array}$ & $\begin{array}{cc}691,100 \\
(\downarrow 5,600) \\
\end{array}$ \\
\hline Colorectal cancer deaths & 244,600 & $\begin{array}{c}233,500 \\
(\downarrow 11,100) \\
\end{array}$ & $\begin{array}{c}242,600 \\
(\downarrow 2,000)\end{array}$ \\
\hline Total costs (discounted) & $\$ 114.7$ billion & $\begin{array}{c}\$ 125.1 \text { billion } \\
(\uparrow \$ 10.4 \text { billion })\end{array}$ & $\begin{array}{l}\$ 119.1 \text { billion } \\
\text { ( } \uparrow \$ 4.4 \text { billion) }\end{array}$ \\
\hline \multirow[t]{2}{*}{$\begin{array}{l}\text { Total number of } \\
\text { colonoscopies }\end{array}$} & 70.3 million & $\begin{array}{c}80.9 \text { million } \\
(\uparrow 10.7 \text { million })\end{array}$ & $\begin{array}{c}73.8 \text { million } \\
\text { ( } \uparrow 3.5 \text { million })\end{array}$ \\
\hline & $\begin{array}{l}\text { Scenario D: } \\
\text { Begin screening at age } 45 \text {, } \\
\text { achieving } 80 \% \text { participation } \\
\text { (colonoscopy } 65 \% \text {, fecal } \\
\text { immunochemical test } 15 \% \text { ) } \\
\text { in all ages } 45-75\end{array}$ & $\begin{array}{c}\text { Scenario E: } \\
\text { Achieve } 80 \% \text { participation } \\
\text { (colonoscopy } 65 \% \text {, fecal } \\
\text { immunochemical test } 15 \% \text { ) } \\
\text { in all ages } 50-75^{\star \star \star}\end{array}$ & $\begin{array}{c}\text { Scenario F: } \\
\text { Hypothetical scenario } \\
\text { without any past or present } \\
\text { screening }\end{array}$ \\
\hline $\begin{array}{l}\text { Screening participation rates } \\
\text { with colonoscopy (white) or } \\
\text { fecal immunochemical test } \\
\text { (black) as a function of age } \\
\text { in years }\end{array}$ & $\begin{array}{r}100 \% \\
80 \% \\
60 \% \\
40 \% \\
200 \% \\
\end{array}$ & \begin{tabular}{c|c}
$.00 \%$ \\
$80 \%$ \\
$60 \%$ \\
$40 \%$ \\
$20 \%$ \\
2
\end{tabular} & -- \\
\hline Colorectal cancer cases & $\begin{array}{c}594,200 \\
(\downarrow 102,500)\end{array}$ & $\begin{array}{c}619,200 \\
(\downarrow 77,500)\end{array}$ & $1,181,100$ \\
\hline Colorectal cancer deaths & $\begin{array}{c}206,100 \\
(\downarrow 38,500)\end{array}$ & $\begin{array}{c}212,800 \\
(\downarrow 31,800)\end{array}$ & 453,400 \\
\hline Total costs (discounted) & $\begin{array}{c}\$ 121.6 \text { billion } \\
(\uparrow \$ 6.9 \text { billion })\end{array}$ & $\begin{array}{l}\$ 118.1 \text { billion } \\
(\uparrow \$ 3.4 \text { billion })\end{array}$ & $\$ 119.1$ billion \\
\hline $\begin{array}{l}\text { Total number of } \\
\text { colonoscopies }\end{array}$ & $\begin{array}{c}85.4 \text { million } \\
(\uparrow 15.1 \text { million })\end{array}$ & $\begin{array}{c}82.3 \text { million } \\
(\uparrow 12.0 \text { million })\end{array}$ & 6.2 million \\
\hline
\end{tabular}

Figure 1.

National clinical and economic outcomes of alternative age-specific screening participation scenarios by age, projected over 5 years. $*$ Numbers in parentheses represent differences versus the comparator Scenario A (current age-specific screening participation patterns in the U.S.). *Projections are based on year 2017 census estimates (135 million people of ages 45-100), ${ }^{26}$ and account for age-band-specific colorectal cancer risk, and current and historical age-band-specific screening participation patterns with colonoscopy and stoolbased screening. $* *$ The 5-year projections with current participation patterns translate into approximately 139,300 colorectal cancer cases and 48,900 colorectal cancer deaths per year nationally at ages 45 and older. For comparison: (1) The estimated number of colorectal cancer cases at ages 45 and older derived from SEER data 2011-2015 and census 2017 
projections is 143,$500 ;^{12,26}$ (2) The estimated numbers of colorectal cancer cases and deaths at ages 45 and older based on published 2018 all-age cancer statistics (140,250 colorectal cancer cases and 50,630 colorectal cancer deaths), ${ }^{25}$ and the fraction of all colorectal cancers occurring at ages 45 and older ( $94 \%$ of all cases) ${ }^{12,26}$ are 132,100 and 47,700, respectively. $* * *$ Participation rates in $45-49$ year-olds reflect current national data. ${ }^{1}$ 


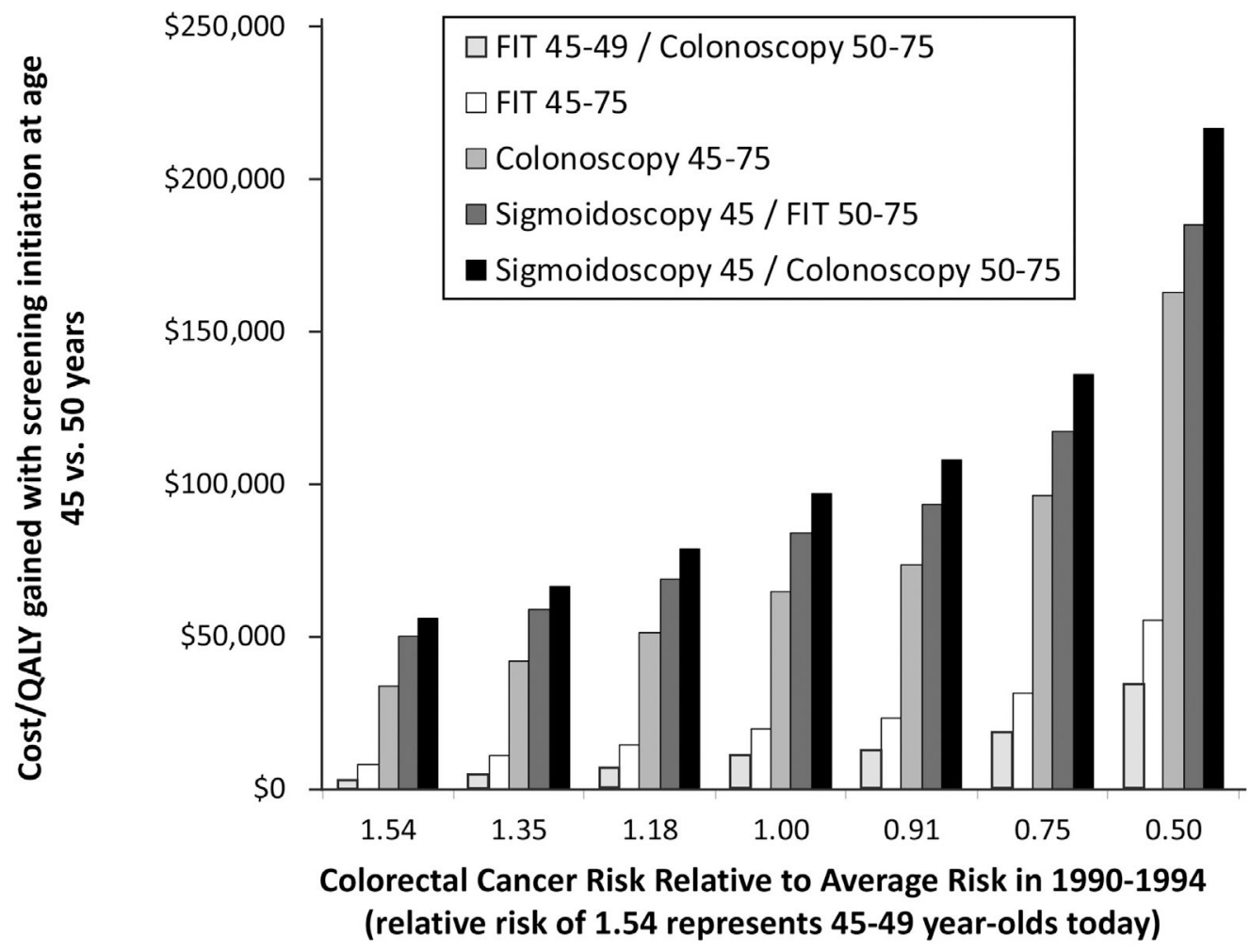

Figure 2.

Cost effectiveness of initiating screening at age 45 vs 50 years as a function of the average CRC risk in the population. Compared with the average risk in 1990-1994, the relative risk of 1.54 represents $45-49$-year-olds today. Relative risks of $1.35,1.18$, and 0.91 represent the level of risk for persons who were 45-49 years old in 2015, 2010, and 1995, respectively. Relative risks of 0.75 and 0.50 , which are, respectively, approximately one half and one third of the risk assumed for today's 45-49-year-olds, reflect persons who may be at lower-thanaverage risk for colorectal cancer, whether due to environmental or heritable factors. For all scenarios, the relative risks that were modeled were assumed to apply over a lifetime, in the absence of screening. For the hybrid strategies, the comparator is the age 50-75-years component of the strategy, and for the single-modality strategies, the comparator is that modality starting at age 50 years. 


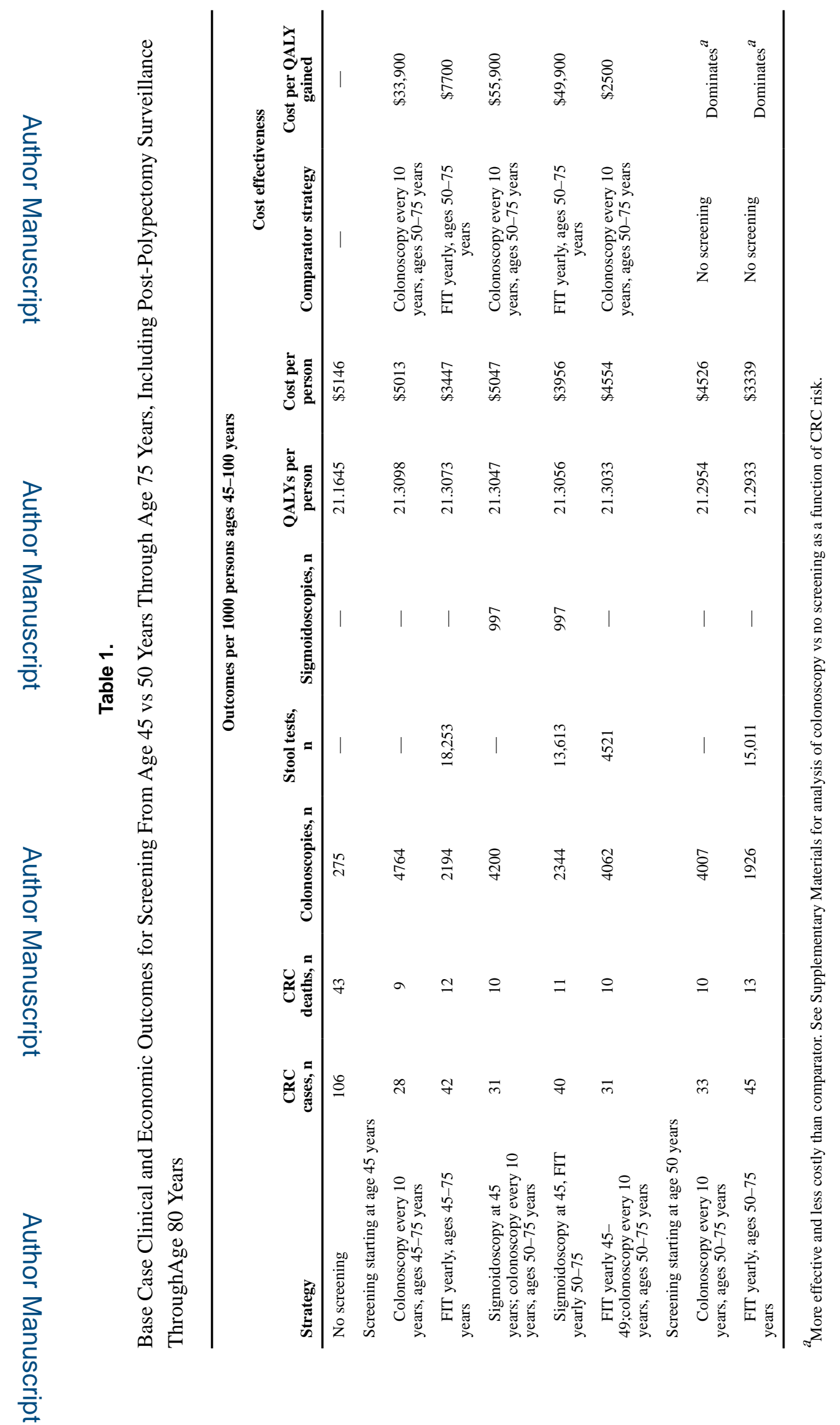

Gastroenterology. Author manuscript; available in PMC 2020 July 01. 


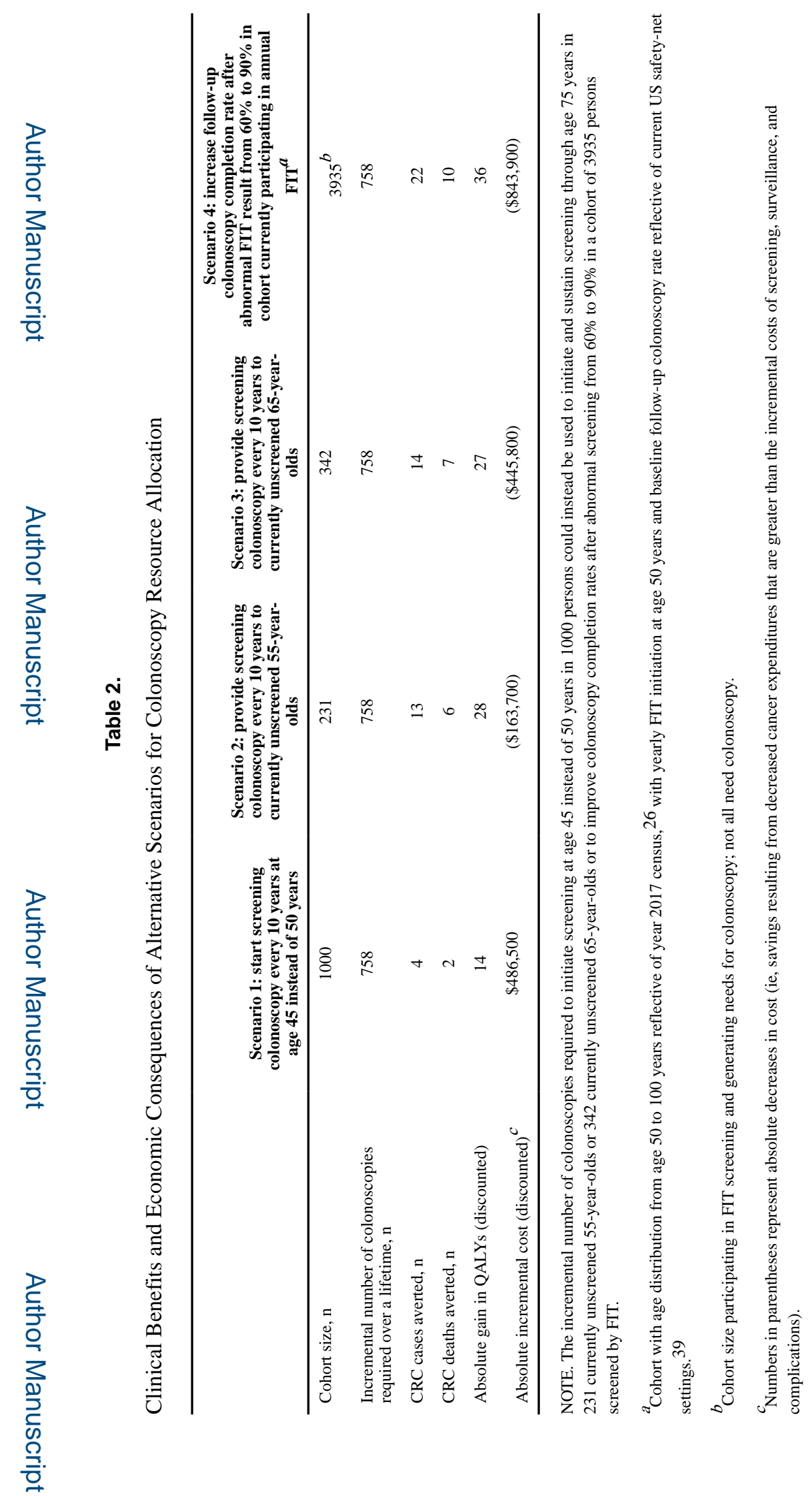

Gastroenterology. Author manuscript; available in PMC 2020 July 01. 


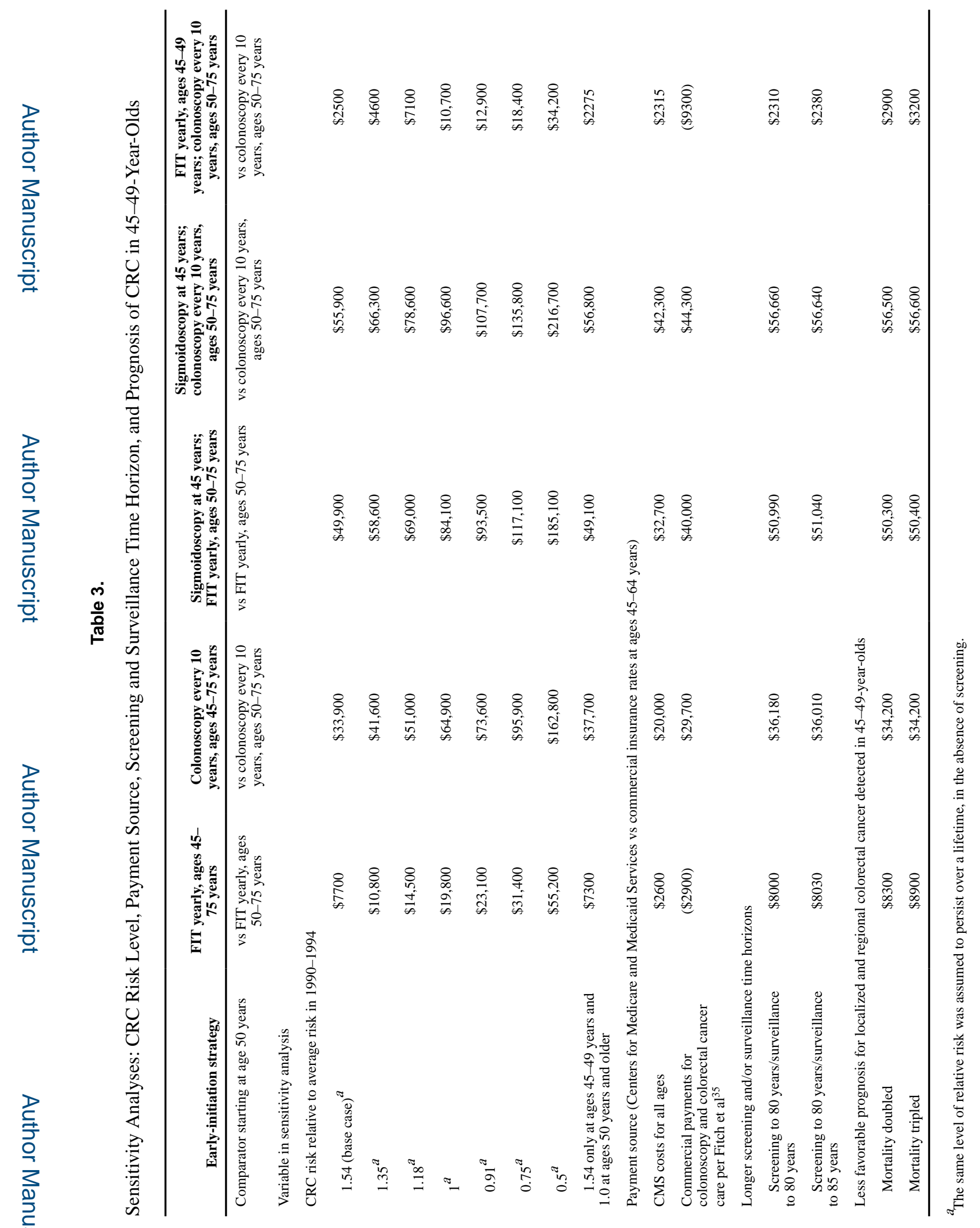

Gastroenterology. Author manuscript; available in PMC 2020 July 01. 